\title{
Pharmacoeconomical evaluation of hypertension with diabetes mellitus in a teaching hospital in urban Bangalore
}

\author{
Rajat Rana $^{1}$, Alekhya Modupalli ${ }^{2}$, Aneena Suresh ${ }^{1}$, Mamidi Santosh $^{3}$, B. Anusha ${ }^{1}$, \\ Sourav Trivedi ${ }^{4}$
}

${ }^{1}$ Department of Pharmacy

Practice, Gautham College of

Pharmacy, Bangalore 560107,

India,

${ }^{2}$ Department of Pharmacy

Practice, Acharya \& B. M

Reddy College of Pharmacy,

Bangalore 560107, India,

${ }^{3}$ Department of Pharmacology,

Gautham College of Pharmacy,

Bangalore 560032, India,

${ }^{4}$ Department of Pharmaceutics,

Gautham College of Pharmacy,

Bangalore 560032, India

Received: 31 January 2016

Accepted: 02 March 2016

*Correspondence to:

Dr. Rajat Rana,

Email: rajatrana91@gmail.com

Copyright: () the author(s), publisher and licensee Medip Academy. This is an openaccess article distributed under the terms of the Creative Commons Attribution NonCommercial License, which permits unrestricted noncommercial use, distribution, and reproduction in any medium, provided the original work is properly cited.

\begin{abstract}
Background: This study was conducted to evaluate Pharmacoeconomics involved in Hypertension with Type II Diabetes in a tertiary care teaching hospital in urban Bangalore.

Methods: The study was conducted among the patients admitted to Inpatient ward of Dr B.R Ambedkar Hospital diagnosed with Type II Diabetes with Hypertension. The data was collected using prevalidated questionnaires which were specially focused on Direct Cost, Indirect Cost \& Intangible Cost. The data was analyzed using SPSS version 20.

Results: The overall mean number of hospitalization days was $5.86 \pm 0.39$. Mean Medication Cost was recorded as Rs $2752 \pm 219.7$. This study also observed that mean laboratory investigation cost were $447.6 \pm 19.66$., Travel expenses Rs $584 \pm 163.9$, Food cost was Rs $324.8 \pm 26.90$ \& lost wages were $1402 \pm 150.5$. The correlation coefficient was highest between food cost and traveling expenses as 0.88 whereas least between lab investigation and lost wages as 0.001 . Thyroid profile test was the costliest test prescribed overall.

Conclusions: This study concludes that the there is a huge economic burden on the patient from the lower income group. Medication cost and diagnostic cost are among the major factors that accounts for the total health care cost.
\end{abstract}

Keywords: Pharmacoeconomics, Medication, Cost, Hospital

\section{INTRODUCTION}

The essential tool in making therapeutic decision in case of chronic diseases like diabetes with hypertension is the pharmacoeconomic evaluations which have grown ahead where there are limited sources. ${ }^{1}$ The process of identifying, measuring and comparing the cost, risks and benefit of programs, services and therapies is called as Pharmacoeconomical research which alternatively produce the best health outcomes for resources invested. ${ }^{2}$
The major health care problem in India which is rapidly increasing especially in urban areas is Diabetes. The prevalence has been increasing steadily in urban areas for type 2 diabetes mellitus from a low $2.1 \%$ reported in early 1970 onwards. $^{3}$ The estimated regional diabetes prevalence in India will be increasing to $10.2 \%$ in 2030 due to increasing life expectancy. ${ }^{4}$ People who are diagnosed with diabetes have medical expenditures approximately 2.3 times higher than the expenditures spend by the people who aren't diagnosed with diabetes. ${ }^{5}$ The prevalence rate of diabetes mellitus in our country is 
1 to $2 \%$ comprising of $0.60 \%$ to $1.93 \%$ of rural population whereas urban population ranges from $0.95 \%$ to $3.8 \%$. In India, the prevalence rate of Diabetes in Bangalore and Hyderabad is $12.9 \%$ and $16 \%$ which was shown in a recent diabetic survey respectively. ${ }^{6}$

Health sources are very limited with only $5 \%$ of GDP spent on healthcare in India \& other parts of developing countries. $^{7}$ In the last decade, research has found that lowering BP in patients with type 2 diabetes has led to sizable reductions in death rates. Many experts believe that lowering blood pressure maybe the most important step than in reducing blood sugar that people with diabetes can take. People having type 2 diabetes \& blood pressure have increase chance of developing other diabetes-related diseases such as retinopathy which may cause kidney disease and blindness. ${ }^{8}$ The cost of hypertension is not just related to the disease itself but also include the costs of future complications. In fact costs associated to renal \& cardiovascular diseases is greater due to more expensive medicines, treatment modalities and also the complexity that is required in medical care. ${ }^{9}$ The use of economic analyses is increasing which is most commonly seen in healthcare management. Since hypertension is most commonly observed and its treatment requires usage of more than a single medication, the antihypertensive drug therapy is most common target for cost-cutting efforts. ${ }^{10}$

The main objective of the study is to evaluate the Pharmacoeconomics involved in treatment of diabetes Type II with hypertension. ${ }^{11}$

\section{METHODS}

Before interviewing the participants, the cost of each item were based on their reports obtained from the medical appointment within the month. Participants of diabetes with hypertension who were under the treatment with both ant diabetics and antihypertensive drugs were included in the Pharmacoeconomical analysis. The sugar level and blood pressure were monitored daily with the help of insulin pen \& sphygmomanometer instruments. ${ }^{12}$

During the month preceding the interview participants who had a consultation were asked about direct healthcare costs including payment for visits to doctor, laboratory tests, purchase of drugs or supplies, health insurance costs and expenses with meals and transportation to the healthcare facility. Investigation of indirect costs was carried out. Direct costs such as expenses spent for meals, transportation and laboratory tests were also considered. Indirect costs were estimated via the proportional per-capita income earned due to productivity losses caused by partial or total absence from work during one working day. The sum of the preceding items was the total cost. The costs of antihypertensive treatment were based on reports from 75 participants regarding monthly expenditure on drugs. On the basis of annual cost, the cost effectiveness relationship of antihypertensive treatment was described. Direct and indirect costs were calculated using means and standard deviation methods in order to compare the expenses spent by the patients having diabetes mellitus with that of hypertensive patients. For each pharmacological group, the cost effectiveness relationship was calculated as the ratio of the annual mean cost with the proportion of patients having controlled hypertension. The cost effectiveness ratio were allowed to be described the cost per patient with controlled diabetes. ${ }^{13}$ The cost effectiveness analysis were stratified by observing the presence of two or three chronic conditions such as hypertension, smoking, diabetes in patients who were more prone to spend money on drugs.

\section{RESULTS}

\section{Estimation of economic burden: Direct cost}

Medication cost is the cost that includes the medicines, and other therapeutic interventions, the data was collected from the pre designed validated data collection form. Forms included the direct cost and socio economic background information about the patient. The data collection form also assessed the data on patients indirect cost and other miscellaneous cost.

The medication cost accounted for the highest cost $(49.9 \%)$ among all the direct and indirect cost. In 74 prescriptions the costliest drug was found to be Syrup Sucralfate Rs 527 and $44.4 \%$ of prescription contains Sucralfate. The second most costliest prescribed drug was Inj.Insulin costing Rs 284.54 in $29.6 \%$ of all the prescriptions. Tab Betahistine was the third costliest drug costing Rs 200 that was prescribed in $59.2 \%$ of all the prescriptions. It was followed by Tab Montelukast costing Rs140 prescribed in $29.6 \%$ of all the prescriptions. The cheapest drug prescribed was Inj. Pantoprazole with cost of Rs 56.8 prescribed in $59.2 \%$ of all the prescriptions.

Table 1: Total overall mean direct cost \& indirect cost in diabetes with hypertension.

\begin{tabular}{|ll|}
\hline Parameters & Mean \pm SEM* \\
\hline Hospitalization days & $5.86 \pm 0.39$ \\
\hline Medication cost & $2752 \pm 219.7$ \\
\hline Lab investigations & $447.6 \pm 19.66$ \\
\hline Travel expenses & $584 \pm 163.9$ \\
\hline Food cost & $324.8 \pm 26.90$ \\
\hline Lost wages & $1402 \pm 150.5$ \\
\hline
\end{tabular}

SEM*: Standard Error of Mean

Hospitalization days comprises of the number days patient is been hospitalized for the cure of the disease is referred to as hospitalization days. The average duration of hospitalization days was 5.86. Although the values ranged from 1 to 19 based upon the complications and 
multiple therapies prescribed. There were no bed charges for the patients admitted to the inpatient ward, so the cost of hospitalization in terms of per day bed charges was almost negligible (Table 1).

Table 2: Total overall mean cost of drugs \& laboratory test in diabetes with hypertension.

\begin{tabular}{|c|c|c|}
\hline Drugs & $\begin{array}{l}\text { Frequency } \\
(\%)\end{array}$ & Cost/prescription \\
\hline Syp. Sucralfate & $44.4 \%$ & Rs 527 \\
\hline Inj.Insulin & $29.6 \%$ & Rs 284.54 \\
\hline Tab.Betahistine & $59.2 \%$ & Rs 200 \\
\hline Tab. Montelukast & $29.6 \%$ & Rs 140 \\
\hline Tab Atorvastatin & $14.9 \%$ & Rs 98.50 \\
\hline Inj.Rabeprazole & $88.8 \%$ & Rs 80 \\
\hline Tab. Telmisartan & $44.4 \%$ & Rs 77 \\
\hline $\begin{array}{l}\text { Tab. Glimiperide } \\
+ \text { Metformin }\end{array}$ & $14.9 \%$ & Rs 73 \\
\hline InjPantaprazole & $59.2 \%$ & Rs 56.8 \\
\hline Lab Test & $\begin{array}{l}\text { Frequency } \\
(\%)\end{array}$ & $\begin{array}{l}\text { Cost/Test } \\
\text { (Rs) }\end{array}$ \\
\hline $\begin{array}{l}\text { Fasting blood } \\
\text { sugar }\end{array}$ & $100 \%$ & 35 \\
\hline CBC with ESR & $97.29 \%$ & 250 \\
\hline $\mathrm{HbA1c}$ & $93.24 \%$ & 50 \\
\hline PPBS \& GRBS & $89.18 \%$ & 450 \\
\hline B.P & $100 \%$ & - \\
\hline Thyroid Profile & $6.75 \%$ & 350 \\
\hline
\end{tabular}

CBC: Complete Blood Count; ESR: Erythrocyte Sedimentation Rate: HbA1c: Glycated hemoglobin, PPBS: Post prandial blood sugar; GRBS: General Random Blood Sugar; B.P: Blood Pressure
Lab Investigation Cost includes nearly all the cases were tested and monitored for fasting blood sugar to detect Type II Diabetes Mellitus and Blood pressure for hypertension. The average lab investigation cost was Rs. 447.6 \pm 19.66 . The second most common lab test performed was CBC with ESR (97.25\%) followed by Glycated hemoglobin (HbA1c). Post prandial blood sugar (PPBS) \& General Random Blood Sugar GRBS was the costliest test performed costing Rs 450 per test. Thyroid profile was conducted less frequently $(6.75 \%)$ when compared to other tests (Table 2).

\section{Indirect cost}

Indirect cost was estimated based upon the loss of wages, food cost, and travelling expenses. Loss of wages is calculated by reported loss and income per day multiplied by the number of hospitalization days. For the nonearning respondents, loss of wages or monetary values of lost man days were estimated using economic value of an individual model (MVI).

The mean loss of wages was calculated as Rs $1402 \pm 150.5$ for an average no of 5 hospitalization days. There was a major difference in the minimum and maximum reported lost wages which ranged from Rs 200 to8000.The food cost was the least expenditure in the entire cost spent by the patient. The food provided to the patient and the family was mostly. The mean Food cost was calculated as Rs324.80 \pm 26.90 . It ranged between Rs 100 to 2000. The travelling expenses were estimated to be Rs $584 \pm 163.9$ ranging between Rs 100 to 4000.Finding out the tangible cost was a major limitation since the cultural and socio economic factors were largely distributed and varied (Table 1).

Table 3: Correlation coefficients between various variables in diabetes with hypertension.

\begin{tabular}{|lllllll|}
\hline $\begin{array}{l}\text { Correlation } \\
\text { coefficients }\end{array}$ & $\begin{array}{l}\text { Hospitalization } \\
\text { days }\end{array}$ & $\begin{array}{l}\text { Medication } \\
\text { cost }\end{array}$ & $\begin{array}{l}\text { Lab } \\
\text { investigations }\end{array}$ & $\begin{array}{l}\text { Travel } \\
\text { expenses }\end{array}$ & Food cost & Lost wages \\
\hline $\begin{array}{l}\text { Hospitalization } \\
\text { days }\end{array}$ & 0.698 & 0.086 & 0.500 & 0.579 & 0.264 \\
\hline $\begin{array}{l}\text { Medication } \\
\text { cost }\end{array}$ & 0.698 & & 0.432 & 0.225 & 0.212 & 0.029 \\
\hline $\begin{array}{l}\text { Lab } \\
\text { investigations }\end{array}$ & 0.086 & 0.432 & & 0.078 & 0.058 & 0.001 \\
\hline $\begin{array}{l}\text { Travelling } \\
\text { expenses }\end{array}$ & 0.500 & 0.215 & 0.078 & & 0.838 & 0.684 \\
\hline Food cost & 0.579 & 0.212 & 0.058 & 0.888 & & 0.610 \\
\hline Lost wages & 0.264 & 0.029 & 0.001 & 0.684 & 0.610 & \\
\hline
\end{tabular}

The correlation coefficient was highest between food cost and traveling expenses as 0.88 whereas least between lab investigation and lost wages as 0.001 (Table 3).

\section{Funding sources}

Almost all the expenditure was remunerated by family and personal resources, irrespective of employment 
status. The house hold savings were used in $69 \%$ of the cases where as $12 \%$ of the cases paid their expenditure by borrowing from the friends or other family relatives. While most of the patients were able to fund the routine care from the personal saving, many had to dip into borrowing the funding from different assets.

\section{DISCUSSION}

This study determined that major part of health care expenditure goes in the medical therapy and laboratory investigations. Other indirect expenses like lost wages, travelling expenses and food cost can be a major factor in determining the total expenditure. This study found a direct positive correlation between number of hospitalization days and medication cost. Also we observed a strong positive correlation between food cost and hospitalization days. The correlation coefficient was highest in Food cost and travel cost which suggests that by reducing the travel cost there can be commensurate reduction in the food cost.

In Bhattacharya $\mathrm{K}$ et $\mathrm{al}^{14}$ study the major treatment cost drivers in patients with type 2 diabetes mellitus in a managed care setting were analysed using retrospective integrated medical and pharmacy claimed data. In a sample of 5171 patients neurological, renal disorders were the third largest treatment cost drug driver. Also they observed high cost of treatment associated with hospitalization episodes, Antidiabetic medications diabetic services, and hemoglobin A1C testing. Age was positively linked with the cost signifying higher cost was coupled with older patients.

Borrell $\mathrm{M}$ et $\mathrm{al}^{15}$ found that the frequency of attendance was directly related to the number of drugs prescribed \& presence of diabetes. A total of 220 hypertensive patients were analysed for the cost involved in controlling hypertension. There was a positive correlation between the number of attendances and hypertension severity. Angiotensin enzyme conversion inhibitors were the greatest monthly mean cost per patient followed by Diuretics being the least. In the case of controlling hypertension the first line treatment represents an increase in the cost that is use of ACEI and calcium antagonists.

Another study by Nichols et al ${ }^{16}$ evaluated the patients whose nephropathy did and did not progress by estimating the level of protein urea of the hypertensive patients with type 2 diabetes to assess the direct medical cost. The progression was considerably associated with $\$ 747$ difference in annualized change in outpatient cost compared with no progression.

In their study they found that patients diagnosed with hypertension along with diabetes illustrated higher subsequent medical care cost in association with progressive nephropathy.
In this study we found that education, knowledge and awareness can be major factors in reducing the economic burden in diabetes mellitus 2 with hypertension. Socioeconomic status can also be a cardinal indicator in understanding the epidemiology of illness and abridging the cost. Also in a study by Ramachandran $\mathrm{A}^{17}$ they found that the patients attending private hospitals at longer diabetes duration compared to those attending public like hospitals. Also they reported that higher income, higher education and higher job opportunities were related in patients in private clinic.

Our study recommends that in a middle income country like India the interventions must be focused on reducing the health expenditure. Various Pharmacoeconomical methods like cost minimization by prescribing generic brands, rationalizing the prescription and early detection of disease and adverse events can largely bring down the cost of health care expenditure. Another dimension can be physicians training to provide acute economic care where the effort and outcomes can be measured objectively and linked to the declining of health expenses. Patient participation in determining his own medication therapy gives him an opportunity to decrease the expenses of the health care.

\section{CONCLUSION}

This study concludes that the there is a huge economic burden on the patient from the lower income group. Medication cost and diagnostic cost are among the major factors that accounts for the total health care cost. Further we concluded that the economic burden increases largely in the presence of multifactorial disorders like Diabetes with hypertension.

\section{Funding: No funding sources}

Conflict of interest: None declared

Ethical approval: The study was approved by the Institutional Ethics Committee

\section{REFERENCES}

1. Ettaro L, Ping Z, Michael M. Cost-of-illness studies in diabetes mellitus. Pharmacoeconomics. 2004;22(3):149-64.

2. Angus C, Walter T, Zwirble L, Lidicker J, Clermont G, Carcillo J. Epidemiology of severe sepsis in the United States: analysis of incidence, outcome, and associated costs of care. Critical care medicine. 2001;29(7):1303-310.

3. Ramachandran A, Snehalatha C, Kapur A, Vijay V, Mohan V, Das A, et al. High prevalence of diabetes and impaired glucose tolerance in India: National Urban Diabetes Survey. Diabetologia. 2001;44(9):1094-101.

4. GuariguataL, Whiting D, Hambleton I, Beagley J, Linnenkamp U, Shaw J. Global estimates of diabetes prevalence for 2013 and projections for 2035. 
Diabetes research and clinical practice. 2014;103(2):137-49.

5. American Diabetes Association. Economic costs of diabetes in the US in 2012. Diabetes care. 2013;36(4):1033-046.

6. Ajay S, Prabhakaran D, Jeemon P, Thankappan K, Mohan V, Ramakrishnan L, et al. Prevalence and determinants of diabetes mellitus in the Indian industrial population. Diabetic Medicine. 2008;25(10): 1187-194.

7. Anderson, Gerard F, Poullier J. Health spending, access, and outcomes: trends in industrialized countries. Health Affairs.1999;18(3):178-92.

8. Barber, Alistair J. A new view of diabetic retinopathy: a neurodegenerative disease of the eye. Progress in Neuro-Psychopharmacology and Biological Psychiatry. 2003;27(2):283-90.

9. Chobanian V, Bakris G, Black H, William C. Cushman A, L Green et al. The seventh report of the joint national committee on prevention, detection, evaluation, and treatment of high blood pressure: the JNC 7 report. Jama. 2003;289(19):2560-71.

10. Alberto B, Aedo C, Rajpathak S, Robles S. The cost of diabetes in Latin America and the Caribbean. Bulletin of the World Health Organization. 2003;81(1):19-27.
11. Marian G, Gasparello B, Ferraro J, Sharma A, Strowe R, Bendek A et.al. Integrated system including medication delivery pen, blood monitoring device, and lancer. U. S. Patent 6,192,891, issued February 27, 2001.

12. UK Prospective Diabetes Study Group. Cost effectiveness analysis of improved blood pressure control in hypertensive patients with type 2 diabetes: UKPDS 40. BMJ: British Medical Journal. 1998;317(7160):720.

13. Alonso J, Garcia M, Laborda M, Hermoso A, Lopez F. Analysis of pharmacologic costs in the treatment of arterial hypertension. Approximation to a costeffectiveness study. Aten Primaria. 1998;21:607-12.

14. Bhattacharyya K, Else B (1999). Medical costs of managed care in patients with type 2 diabetes mellitus. ClinTher. 1999;21(12):2131-42.

15. Borrell M, Ramon J. Pharmaceutical price regulation. Pharmacoeconomics.1991:15(3):291-03.

16. Nichols A, Vupputuri S, Lau H. Medical care costs associated with progression of diabetic nephropathy. Diabetes Care. 2011;34(11):2374-8.

17. Ramachandran A. Socio-economic burden of diabetes in India. Journal Association of Physicians of India. 2007;55:9.

Cite this article as: Rana R, Modupalli A, Suresh A, Mamidi S, Anusha B, Trivedi S. Pharmacoeconomical evaluation of hypertension with diabetes mellitus in a teaching hospital in urban Bangalore. Int $\mathbf{J}$ Basic Clin Pharmacol 2016;5:473-7. 